\title{
Definition of headwater catchment boundaries
}

\author{
Petr Kavka $^{\mathrm{a}}{ }^{*}$, Luděk Strouhal ${ }^{\text {a }}$, Jiří Cajthaml ${ }^{\text {a }}$ \\ ${ }^{a}$ CTU in Prague,petr.kavka@fsv.cvut,cz,luděk.strouhal@fsv.cvut.cz jiri.cajthaml@fsv.cvut.cz
}

Keywords: Headwater catchment, classification

\section{Abstract:}

The aim of the contribution is to present approaches, classification and subsequent cartographic representation of small headwater catchments (SHC) based of their potential hydrological response in Czech Republic. The characteristics of SHC are key to the formation of runoff, especially from spring areas. These catchments characteristics can have an impact not only on the processes in the river basins themselves, but also on the processes further downstream. SHC were classified in several size classes according to the following classes.

\begin{tabular}{|l|c|c|}
\hline \multicolumn{1}{|c|}{ Class } & From $\mathrm{km}^{2}$ & To $\mathrm{km}^{2}$ \\
\hline 005 & 0.3 & 0.7 \\
\hline 010 & 0.7 & 1.3 \\
\hline 020 & 1.7 & 2.3 \\
\hline 030 & 2.7 & 3.3 \\
\hline 040 & 3.5 & 4.5 \\
\hline 050 & 4.5 & 5.5 \\
\hline
\end{tabular}

DEM data with a resolution of $5 \times 5 \mathrm{~m}$ and the watercourses and water bodies from ZABAGED (The Fundamental Base of Geographic Data of the Czech Republic) were used for the estimation of these SHC. The tools of the Esri environment in combination with the Python scripting language were used to define it. An example of SHC delimitation is portrayed in the following figure.

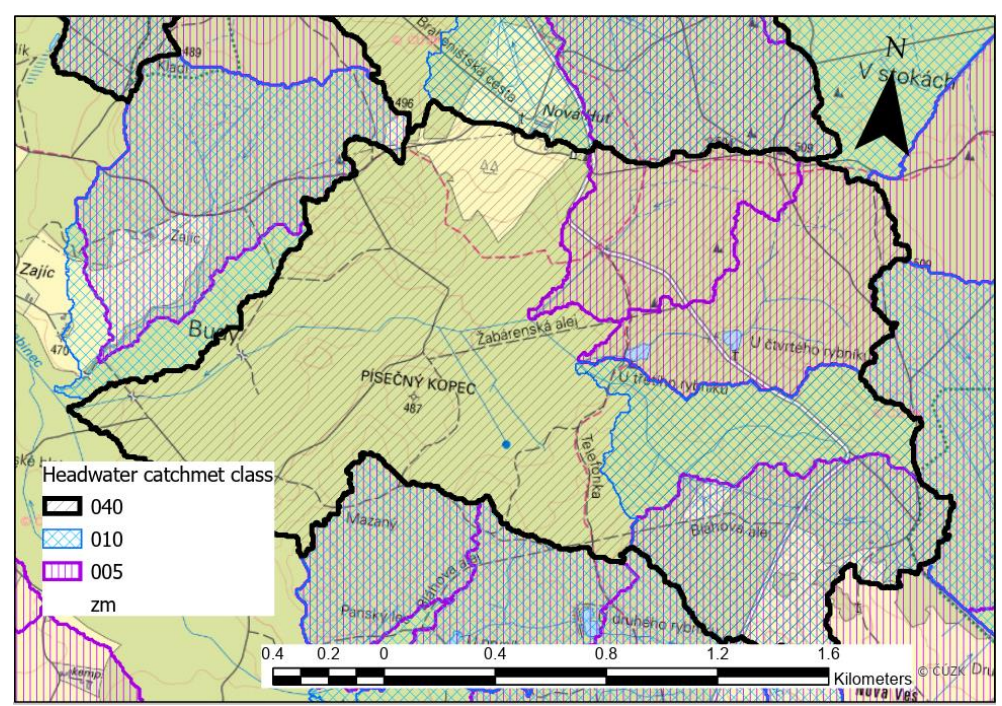

Figure 1. Boundary of SHC in three size classes.

More than 30 parameters that can have influence to the hydrological response were subsequently calculated for SHC thus defined. Statistically independent parameters were selected from more than 30 parameters. These selected parameters serve to classify SHC in terms of their characteristics. This classification is motivated by the assumption that the basins with similar characteristics will have a similar outflow response. Selected characteristics include stream network densify, flow accumulation, slope, SCS - CN value, catchment shape characteristics, etc.

The presentation of final maps and the possibilities of cartographic visualization of aggregated results from small spatial objects on the result maps of their map display is part of the published results.

This contribution was supported by grant of the Ministry of Agriculture - QK1910029 “Antecedent saturation and design rainfalls as factors of hydrological response in small catchments". 